MedienPädagogik

medienpaed.com

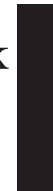

Douglas Kellner and Jeff Share

\section{Media Literacy in the US}

Media literacy education is not as advanced in the US as in several other English-speaking areas such as Great Britain, Canada, and Australia. Despite decades of struggle since the 1970s by individuals and groups, media education is still only reaching a small percentage of Americans. While some major inroads have been made, such as getting elements of media literacy included in most of the 50 state's educational standards and the launching of two national media education organizations, most teachers and students in the United States still have never heard of media literacy. In this paper, we first set forth some models of media literacy, delineate key concepts of critical media literacy, and then examine some of the most active organizations in the United States and differences in their goals and pedagogy.

\section{Models of Media Literacy}

Literacy involves gaining the skills and knowledge to read and interpret varying texts and artifacts, and to successfully navigate and negotiate their challenges, conflicts, and crises. To the domains of reading, writing, and traditional print literacies, one could argue that in an era of technological revolution, educators must develop robust forms of media literacy, computer literacy, and multimedia literacies, thus cultivating «multiple literacies» in the restructuring of education. Computer and multimedia technologies demand novel skills and competencies, and if education is to be relevant to the problems and challenges of contemporary life engaged teachers must expand the concept of literacy and develop new curricula and pedagogies.

Both traditionalists and reformists would probably agree that education and literacy are intimately connected. «Literacy», in our conception, comprises gaining competencies involved in effectively learning and using sociallyconstructed forms of communication and representation. Learning literacies involves attaining competencies in practices in contexts that are governed by rules and conventions. Literacies are socially constructed in educational and cultural practices involved in various institutional discourses and practices. Literacies evolve and shift in response to social and cultural change and the interests of elites who control hegemonic institutions.

We would resist, however, extreme claims that the era of the book and print literacy are over. Although there are new media and literacies in current constellation, books, reading, and print literacy continue to be of utmost significance. Indeed, in the new information-communication technology environment, traditional print literacy takes on increasing importance in the computer-mediated cyberworld as people need to critically scrutinize and scroll tremendous amounts of information, putting new emphasis on developing reading and writing abilities. For instance, Internet discussion groups, chat rooms, e-mail, blogs, wikis, and various Internet forums require writing skills in which a new emphasis on the importance of clarity and precision is emerging. ${ }^{1}$ In this context of information saturation, it becomes an ethical imperative not to contribute to cultural and information overload, and to concisely communicate thoughts and feelings.

In the new multimedia environment, media literacy is arguably more important than ever. Cultural studies and critical pedagogy have begun to teach us to recognize the ubiquity of media culture in contemporary society, the growing trends toward multicultural education, and the need for media literacy that addresses the issue of multicultural and social difference. ${ }^{2}$ There is expanding recognition that media representations help

${ }^{1}$ On the new forms of Internet culture and on-line communities, see Kahn and Kellner 2003.

2 For an earlier and expanded discussion of media literacy, see Kellner 1998. Carson and Friedman 1995 contains studies dealing with the use of media to deal with multicultura education. Examples of teaching media literacy which I draw on include Masterman 1985; Kellner and Ryan 1988; Schwoch, White and Reilly 1992; Fleming 1993; Giroux 1992, 1993, 1994, and 1996; Giroux and McLaren 1994; Sholle and Densky 1994; 1992, 1993, 1994, and 1996; Giroux and McLaren 1994; Sholle and Densky 1994; 1997a and 1997b; Giroux and Shannon 1997; Potter 1998; and Semali and Watts 
construct our images and understanding of the world and that education must meet the dual challenges of teaching media literacy in a multicultural society and sensitizing students and publics to the inequities and injustices of a society based on gender, race, and class inequalities and discrimination. Recent critical studies see the role of mainstream media in exacerbating or diminishing these inequalities and the ways that media education and the production of alternative media can help create a healthy multiculturalism of diversity and more robust democracy. They confront some of the most serious difficulties and problems that currently face us as educators and citizens.

Feminist theory and standpoint epistemologies provide major contributions to the field of critical media literacy. For example, Carmen Luke combines cultural and feminist studies which allow for an «epistemological standpoint which acknowledges difference(s) of identity, the cultural constructedness of 〈Theory〉, 〈History〉, and 〈Truth〉, and the cultural dynamics of our own labor as academic researchers and teachers». Recognition of media misrepresentation and stereotyping links with a feminist «commitment to a politics of transformation», according to Luke. ${ }^{4}$ This requires unveiling the political and social construction of knowledge, as well as addressing principles of equity and social justice related to representation. Through the inclusion of some groups and exclusion of others, representations benefit dominant and positively represented groups and disadvantage marginalized and subordinate ones.

These biases become especially pernicious when two factors exist: 1) limited and dominant groups do the majority of the representing, as in the case of the multinational corporate mass media; and 2) when the messages are naturalized, people seldom question the transparent social construction of the representations. Luke argues that it is the teacher's responsibility

Pailliotet 1999. See also the work of Barry Duncan and the Canadian Association for Media Literacy (website: http://www.nald.ca/province/que/litcent/media.htm) and the Los Angeles based Center for Media Literacy (www.medialit.org). It is a scandal that there are not more efforts to promote media literacy throughout the school system from K-12 and into the University. Perhaps the ubiquity of computer and multimedia culture will awaken educators and citizens to the importance of developing media literacy to create individuals empowered to intelligently access, read, interpret, and criticize contemporary media and cyberculture.

3 Carmen Luke, «Feminist pedagogy and critical media literacy», Journal of Communication Inquiry v18, n2 (Summer, 1994): 30 (18 pages), 33

4 Ibid. 32.

$3 / 21$ within the classroom to make visible the power structure of knowledge and how it benefits some more than others. She insists «that a commitment to social justice and equity principles should guide the media educator's work in enabling students to come to their own realizations that, say, homophobic, racist or sexist texts or readings, quite simply, oppress and subordinate others». ${ }^{5}$

Further, a student-centered, bottom-up approach is necessary for a standpoint analysis to come from the student's own culture, knowledge, and experiences. Luke suggests that collaborative inquiry and video production can be ways for students to voice their discoveries. While these practical suggestions are congruent with much current advice on media literacy education, Luke asserts the need to take media education beyond just analyzing the production of meaning. She writes that critical media studies must «extend to explorations of how individual and corporate sensemaking tie in with larger socio-political issues of culture, gender, class, political economy, nation, and power». ${ }^{6}$

Feminist standpoint theory thus offers important concepts for seeing through the naturalization of the dominant perspective. Sandra Harding suggests we begin our attempt to perceive and understand phenomena from the standpoint of marginalized groups in order to gain multiple perspectives on issues and phenomena that appear as common sense. Feminist and critical pedagogy both stress the importance of valuing students' voices for deconstructing media as well as creating their own. The process of empowerment is a major aspect of transformative education and it can take many forms, from building self-esteem to creating alternative media that voices opposition to social problems.

Yet despite the ubiquity of media culture in contemporary society and everyday life, and the recognition that the media themselves are a form of pedagogy, and despite criticisms of the distorted values, ideals, and representations of the world in popular culture, media education in K-12 schooling in the US has never really been established and developed. The current technological revolution, however, brings to the fore, more than ever, the role of media like television, popular music, film, and advertising, as the Internet rapidly absorbs these cultural forms and creates new cyberspaces and forms of culture and pedagogy.

\section{Ibid., 44 \\ ${ }^{6}$ Ibid., 31.}


It is highly irresponsible in the face of saturation by Internet and media culture to ignore these forms of socialization and education; consequently a critical reconstruction of education should produce pedagogies that provide media literacy and enable students, teachers, and citizens to discern the nature and effects of media culture. From this perspective, media culture is a form of pedagogy that teaches proper and improper behavior, gender roles, values, and knowledge of the world (Kellner, 1995). Individuals are often not aware that they are being educated and constructed by media culture, as its pedagogy is frequently invisible and subliminal. This situation calls for critical approaches that make us aware of how media construct meanings, influence and educate audiences, and impose their messages and values. Critical media literacy involves cultivating skills in analyzing media codes and conventions, abilities to criticize stereotypes, dominant values, and ideologies, and competencies to interpret the multiple meanings and messages generated by media texts. Media literacy helps people to use media intelligently, to discriminate and evaluate media content, to critically dissect media forms, and to investigate media effects and uses.

Within educational circles, however, a debate persists over what constitutes the field of media pedagogy, with different agendas and programs. A traditionalist «protectionist» approach would attempt to «inoculate» young people against the effects of media addiction and manipulation by cultivating a taste for book literacy, high culture, and the values of truth and beauty, and by denigrating all forms of media and computer culture (see Postman 1985, 1992). A «media literacy» movement, by contrast, attempts to teach students to read, analyze, and decode media texts, in a fashion parallel to the advancement of print literacy. Media arts education, in turn, teaches students to appreciate the aesthetic qualities of media and to use various media technologies as instruments of self-expression and creation. Critical media literacy builds on these approaches, analyzing media culture as products of social production and struggle, and teaching students to be critical of media representations and discourses, but also stressing the importance of learning to use the media as modes of selfexpression and social activism (Kellner 1995).

Developing critical media literacy involves perceiving how media like film or video can be used positively as well to teach a wide range of topics, like multicultural understanding and education. If, for example, multicultural education is to champion genuine diversity and expand the curriculum, it is important both for groups marginalized from mainstream education to learn about their own heritage and for dominant groups to explore the experiences and voices of minority and oppressed groups. When groups often underrepresented or misrepresented in the media become investigators of their representations and creators of their own meanings, the learning process becomes an empowering expression of voice.

Thus, critical media literacy can promote multicultural literacy, conceived as understanding and engaging the heterogeneity of cultures and subcultures that constitute an increasingly global and multicultural world (Courts 1998; Weil 1998). Critical media literacy not only teaches students to learn from media, to resist media manipulation, and to use media materials in constructive ways, but is also concerned with developing skills that will help create good citizens and that will make individuals more motivated and competent participants in social life. Critical media literacy is tied to the project of radical democracy and concerned to develop skills that will enhance democratization and participation. It takes a comprehensive approach that would teach critical skills and how to use media as instruments of social communication and change. The technologies of communication are becoming more and more accessible to young people and ordinary citizens, and can be used to promote education, democratic self-expression, and social progress. Technologies that could help produce the end of participatory democracy, by transforming politics into media spectacles and the battle of images, and by turning spectators into cultural zombies, could also be used to help invigorate democratic debate and participation (Kellner 1990, 1998).

Indeed, teaching critical media literacy should be a participatory, collaborative project. Watching television shows or films together could promote productive discussions between teachers and students (or parents and children), with emphasis on eliciting student views, producing a variety of interpretations of media texts and teaching basic principles of hermeneutics and criticism. Students and youth are often more media savvy, knowledgeable, and immersed in media culture than their teachers, and can contribute to the educational process through sharing their ideas, perceptions, and insights. Along with critical discussion, debate, and analysis, teachers ought to be guiding students in an inquiry process that deepens their critical exploration of issues that affect them and society. Since media culture is often part and parcel of students' identity and most powerful cultural experience, teachers must be sensitive in criticizing artifacts and 
perceptions that students hold dear, yet an atmosphere of critical respect for difference and inquiry into the nature and effects of media culture should be promoted.

A major challenge in developing critical media literacy, however, results from the fact that it is not a pedagogy in the traditional sense with firmlyestablished principles, a canon of texts, and tried-and-true teaching procedures. It requires a democratic pedagogy which involves teachers sharing power with students as they join together in the process of unveiling myths and challenging hegemony. Critical media pedagogy in the US is in its infancy; it is just beginning to produce results, and is more open and experimental than established print-oriented pedagogy. Moreover, the material of media culture is so polymorphous, multivalent, and polysemic, that it necessitates sensitivity to different readings, interpretations, perceptions of the complex images, scenes, narratives, meanings, and messages of media culture which in its own ways is as complex and challenging to critically decipher as book culture.

Teaching critical media literacy involves occupation of a site above the dichotomy of fandom and censor. One can teach how media culture provides significant statements or insights about the social world, empowering visions of gender, race, and class, or complex aesthetic structures and practices, thereby putting a positive spin on how it can provide significant contributions to education. Yet we ought to indicate also how media culture can advance sexism, racism, ethnocentrism, homophobia and other forms of prejudice, as well as misinformation, problematic ideologies, and questionable values, accordingly promoting a dialectical approach to the media.

\section{Critical Media Literacy: Some Conceptual Definitions}

Since the 1980s when Len Masterman first wrote Teaching the Media, many media educators around the world have embraced a set of key concepts. The Center for Media Literacy (CML) has taken many of these foundational ideas of media literacy and simplified them into a framework that is more accessible to teachers and applicable for students. The CML MediaLit $\mathrm{Kit}^{T M}$ identifies five core concepts that lie at the heart of media literacy and can be understood as follows:

\section{Core Concept \#1 Principle of Non-Transparency}

All media messages are «constructed»

The first core concept is the foundation of media literacy, which challenges the power of media to present messages as non-problematic and transparent. Semiotics, the science of signs and how meanings are socially produced from the structural relations in sign systems, has contributed greatly to media literacy. Roland Barthes explains that semiotics aims to challenge the naturalness of a message, the "what-goes-with-out-saying». ${ }^{7}$ Masterman asserts that the foundation of media education is the principle of nontransparency. Media do not present reality like transparent windows or simple reflections of the world because media messages are created, shaped, and positioned through a construction process. This construction involves many decisions about what to include or exclude and how to represent reality. Masterman explains non-transparency with a pun: «the media do not present reality, they re-present it». ${ }^{8}$ Henry Giroux writes, «What appears as «natural〉 must be demystified and revealed as a historical production both in its content, with its unrealized claims or distorting messages, and in the elements that structure its form». ${ }^{9}$ Demystifying media messages through critical inquiry is the heart of media literacy.

\section{Core Concept \#2 Codes and Conventions}

Media messages are constructed using a creative language with its own rules

The second core concept also relies heavily on semiotics to illustrate how signs and symbols function. From the study of semiotics, media literacy practitioners analyze the existence of dual meanings of signs: denotation and signifier (the more literal reference to content) and connotation and signified (the more associative, subjective significations of a message based on ideological and cultural codes).$^{10}$ When connotation and denotation become one and the same, representation appears natural, making the historical and social construction invisible. Therefore, a goal of cultivating

Roland Barthes, Mythologies, (New York: Hill and Wang, 1998), 11

'Len Masterman, «The Development of Media Education in Europe in the 1980s», Metro: Magazine of the Australian Teachers of Media, (autumn 1989): 5 pages.

${ }^{9}$ Henry A. Giroux, Pedagogy and the Politics of Hope: Theory Culture and Schooling, (Boulder, CO: Westview Press, 1997), 79-80.

${ }^{10}$ Stuart Hall, Encoding/Decoding in Stuart Hall, Dorothy Hobson, Andrew Lowe an Paul Willis (eds.), Culture, Media, Language (London: Hutchinson, 1980). 
media literacy is to help students distinguish between connotation and denotation and signifier and signified. ${ }^{11}$ With younger students the terms are simplified into separating what they see or hear from what they think or feel. Here again, creating media proves to be a powerful vehicle for guiding students to explore these ideas.

For example, discussion of the representation of class, gender, and race in media such as television or film requires analysis of the codes and stereotypes through which subordinate groups like workers, women, and people of color are represented, in contrast to representations of bosses and the rich, men, and white people. Analysis of different models of representation of women or people of color makes clear the constructedness of gender and race representations and that dominant negative representations further subordination and make it look natural. Thus while signifiers that represent male characters like Arnold Schwarzenegger seem to just present a male actor, they construct connotative meanings and signify certain traits such as patriarchal power, violent masculinity, and dominance. Media are thus highly coded and constructed and are not windows on the world.

\section{Core Concept \#3 Audience Decoding}

Different people experience the same media message differently

The third core concept evolves from work at the Birmingham Centre for Contemporary Cultural Studies in the U. K. where the notion of an active audience challenged previous theories that viewed receivers of media as passive recipients and often victims. Building on semiotic conceptions developed by Roland Barthes and Umberto Eco, Stuart Hall argued that a distinction must be made between the encoding of media texts by producers and the decoding by consumers in a study of «Encoding/decoding». This distinction highlighted the ability of audiences to produce their own readings and meanings, to decode texts in aberrant or oppositional ways, as well as the «preferred» ways in tune with the dominant ideology. ${ }^{12}$

The cultural studies approach provides a major advance for understanding literacy as Ien Ang explains: «Textual meanings do not reside in the texts themselves: a certain text can come to mean different things depending on

${ }^{11}$ John Fiske, Introduction to Communication Studies, $2^{\text {nd }}$ ed., (London: Routledge, 1990), 87.

${ }^{12}$ Stuart Hall, «Encoding/decoding». In Centre for Contemporary Cultural Studies, $\mathrm{Cul}$ ture, Media, Language. London: Hutchinson, 1980: 128-138, op. cit. the interdiscursive context in which viewers interpret it». ${ }^{13}$ The notion that audiences are neither powerless nor omnipotent when it comes to reading media contributes greatly to the potential for media literacy to empower audiences in the process of negotiating meanings. As bell hooks puts it «While audiences are clearly not passive and are able to pick and choose, it is simultaneously true that there are certain 〈received messages that are rarely mediated by the will of the audience». ${ }^{14}$ Empowering the audience through critical thinking inquiry is essential for students to challenge the power of media to create preferred readings. Audience theory views the moment of reception as a contested terrain of cultural struggle where critical thinking skills offer potential for the audience to negotiate different readings and openly struggle with dominant discourses.

The ability for students to see how diverse people can interpret the same message differently is important for multicultural education since understanding differences means more than merely tolerating one and other. Research, for example, has shown that the US-television series Dallas has very different cultural meanings for people in various countries and that Dutch and Israeli audiences, for instance, decode it very differently than American audiences. Likewise, different subject positions like gender, race, class, or sexuality will also produce different readings and one's grasp of a media text is enriched by interpreting from the standpoint of different audience perspectives.

This process of grasping different audience readings and interpretations enhances democracy as multicultural education for a pluralistic democracy depends on a citizenry that embraces multiple perspectives as a natural consequence of varying experiences, histories, and cultures constructed within structures of dominance and subordination. Feminist Standpoint Epistemologies offer a starting point for this type of inquiry by beginning all analysis from a subordinate position the preferred hegemonic readings are denaturalized and exposed as merely one of many ways to understand the message. Understanding dissimilar ways of seeing is essential to understanding the

${ }^{13}$ Ien Ang, «On the Politics of Empirical Audience Research» in Meemakshi Gig Durham and Douglas M. Kellner, eds., Media and Cultural Studies Key Works, (Malden: Blackwell Publishers, 2002),180.

${ }^{14}$ Bell Hooks, Reel to Real: Race, Sex, and Class at the Movies, (New York: Routledge, 1996), 3 
politics of representation. John Berger writes, «The way we see things is affected by what we know or what we believe». ${ }^{15}$

\section{Core Concept \#4, Content and Message}

Media have embedded values and points of view

The fourth core concept focuses on the actual content of media messages in order to question ideology, bias and the connotations explicit and implicit in the representation. Cultural Studies, Feminist Theory and Critical Pedagogy offer arsenals of research for this line of inquiry to question media representations of race, class, gender, etc. Beyond simply locating the bias in media, this concept helps students recognize the subjective nature of all communication. Henry Giroux states, «The notion that theory, facts, and inquiry can be objectively determined and used falls prey to a set of values that are both conservative and mystifying in their political orientation». ${ }^{16}$

For example, reading the content of a TV-series like Buffy, the Vampire Slayer discerns more positive representations of young women than are typical in a mainstream media artifact and sends out messages of young female empowerment. The positive representations of gays and lesbians on the show also send messages that suggest more multiple and pluralistic representations of sexuality than is usual on US-network TV programs (although representations of sexuality have greatly expanded over the pas decade). The monsters on Buffy can be read as signifying dangers of drugs, rampant sexuality, or gangs producing destructive violence. Content is often highly symbolic and thus requires a wide range of theoretical approaches to grasp the multidimensional social, political, moral, and sometimes philosophical meanings of a cultural text.

\section{Core Concept \#5, Motivation}

Media are organized to gain profit and/or power

The fifth concept encourages students to consider the question of why the message was sent and where it came from. Too often students believe the role of media is simply to entertain or inform, with little knowledge of the economic structure that supports it. Where once there were many media outlets in every city competing for viewers and readers, today there are less than ten transnational corporations that dominate the global media market. ${ }^{17}$

\footnotetext{
${ }^{15}$ John Berger, Ways of Seeing, (London: British Broadcasting Corporation, 1977), 8.

${ }^{16}$ Henry Giroux, Pedagogy and the Politics of Hope, 11

${ }^{17}$ Robert W. McChesney, «The New Global Media: It's a Small World of Big
}

$11 / 21$
The consolidation of ownership of the mass media has given control of the public airwaves to a few multinational oligopolies to determine who and what is represented and how. This concentration of ownership threatens the independence and diversity of information and creates the possibility for the global colonization of culture and knowledge. Robert McChesney insists that the consolidated ownership of the media giants is highly undemocratic, fundamentally noncompetitive, and «more closely resembles a cartel than it does the competitive marketplace found in economics textbooks». ${ }^{18}$

For example, mainstream media in the United States tended to favorably present George W. Bush in the 2000 election because, in part, the conservative Republican agenda of the Texas governor was in line with the corporate interests of media companies that favored deregulation, absence of impediments to corporate mergers, and tax breaks for their wealthy employees and advertisers. Certain media corporations, like Rupert Murdoch's Fox television network, pursue aggressively rightwing agendas in line with the corporate interests of its owner, board of directors, and top executives who closely follow Murdoch's conservative line. Thus, knowing what sort of corporation produces a media artifact, or what sort of system of production dominates given media, will help to critically interpret biases and distortions in media texts.

\section{National Organizations}

In various areas across the US there are dozens of organizations and individuals teaching critical thinking skills about media to students, teachers, community members, inmates, health care professionals, and others. The US now has two national media literacy membership organizations that hold national conferences every two years, support a variety of media literacy activities, and have about 400 members each.

The larger of the two organizations, Alliance for a Media Literate America (AMLA), founded in 2001 is an umbrella organization of many independen media literacy organizations. AMLA attempts to unite media literacy organizations as well as commercial media makers, whereas the other national ML organization takes an ardent position against any type of commercial collaboration or sponsorship. While the two groups have

Conglomerates», The Nation, v269, n18, (November 29, 1999).

${ }^{18}$ Ibid., 13 
similar goals, their philosophical differences reflect a fissure in media education in the US.

Founded in 2002, Action Coalition for Media Education (ACME) rejects any ties to corporate media and supports an activist position in relation to media regulation and ownership. At the founding of ACME, Sut Jhally, founder and executive director of the Media Education Foundation, described the division within the media literacy movement in the US as a difference in starting points. He suggests that many begin their analysis stressing the literacy aspect of messages, while the correct starting point should instead stress the context of the message. Jhally's institutional analysis reflects the ACME focus on the media part of media literacy. However, Faith Rogow, former president of AMLA, asserts that stressing media over literacy is pedagogically «fatally flawed». ${ }^{19}$ She suggests that by placing the primary focus on literacy, media literacy will become more of an academic field than a movement. This division reveals key differences between AMLA's more liberal educational approach and ACME's more radical advocacy position.

A heated point of debate between the two groups involves a TV program in public schools known as Channel One. This 10-minute news program with 2 minutes of commercials is piped into about 12,000 schools across the US in exchange for free TVs and VCRs. While neither AMLA nor ACME support Channel One, their responses are quite different. ACME takes a firm stance opposing all aspects of Channel One and refuses to accept any funding from them or any commercial media outlet. AMLA, on the other hand, reaches out to commercial media and seeks any sponsor who shares their vision, be it corporate or private. Partnership for Media Education, the predecessor of AMLA, took funding from Channel One for a national media literacy conference and one of AMLA's principal founders created a media literacy curriculum for them.

While many media educators are members of both organizations, personal differences between some of the leaders have hindered collaborations. Media education in the US is having more success on smaller levels by hard working individuals and small organizations. One example of success can be seen in the unconnected work by people across the country to ad-

${ }^{19}$ Faith Rogow, «Shifting from Media to Literacy: One Opinion on the Challenges of Media Literacy Education», American Behavioral Scientist, v48, n1 (September 2004): (4 pages) 30

$13 / 21$ vance media literacy concepts into state standards, a process we examine in the next section

\section{Educational Standards}

Today, most of the 50 states in the US make some mention of media education in their educational standards. Frank Baker created a matrix of media literacy standards in different states that identify under which subject matter media education can be found in each state's standards. For example, in California, the State Department of Education lists the category «Analysis and Evaluation of Oral and Media Communications» as part of Language Arts for third through twelfth grades. In Texas, media education is included in the state standards under the heading of Viewing and Representing within Language Arts Standards from fourth grade on The closest equivalent the United States has to national educational standards can be found at the Mid-continent Research for Education and Learning (McRel) organization. This private non-profit is a leader in educational standards for many state departments of education. Online they list Viewing (Uses viewing skills and strategies to understand and interpret visual media) and Media (Understands the characteristics and components of the media) as two of the five components of Language Arts. While media education is now expected to be taught since it is listed in all the state standards, unfortunately little has been done to train teachers or create curriculum.

\section{Training}

Teacher training programs that specifically focus on media education in the US are few and far between. Only a few organizations from New Mexico to New York offer annual weeklong workshops like the New Mexico Media Literacy Project's Catalyst Institute or Project Look Sharp's Media Literacy Summer Institute. Other groups offer shorter trainings with more frequency, like the Center for Media Literacy's Crash Course, a 4-hour workshop that has been running for almost twenty years.

More recently, the Media Education Lab at Temple University began offering workshops for teachers in the Philadelphia area and the University of Southern California's Annenberg Center began training teachers through their Institute for Multimedia Literacy. Scattered across the US are universities and colleges offering a course or two in media education, usually dependent on a professor who happens to have a special interest in the 
subject. While many individuals and organizations are teaching media literacy, in comparison to the immense size of the US population, the percentage of media education actually happening is extremely small.

A few universities in the US now offer comprehensive academic programs in media education. In North Carolina, Appalachian State University offers a Master's of Arts in Educational Media. This program was founded in 2000 by Australian David Considine, who also runs an annual summer institute in media literacy at the university. Webster University in Missouri offers both a BA and MA with emphasis in media literacy. It is more common to find a critical media class in a communication department than in a school of education. A big challenge for media literacy in the US is thus to enter into teacher training programs and departments of education.

\section{The Educational Political Pendulum in the $21^{\text {st }}$ Century}

Most teacher training and staff development in the US rarely mention media education or discuss media literacy concepts. This is still a brand new subject in the States and has little awareness or support from many faculty and administrators. The current obsession with standardized high stakes testing and the movement back to basics that has bumped critical thinking to the periphery promoted by the Bush administration and conservative educators makes the implementation of media education in the US even more difficult.

In California, scripted phonics-based programs that aim to have every child on «the same page at the same time» have replaced constructivist based «Core Literature» and «Whole Language» programs that were much more creative and child-centered. This positivist approach emphasizes memorization and testing skills over exploration and inquiry. It is movement away from the progressive advances of Dewey and critical pedagogy and a return to what Paulo Freire called «banking education».

Along with the back to basics is an anti-immigrant English-only agenda. During the 1990s in California, a series of state propositions attacked immigrants (prop 187), dismantled affirmative action (prop 209), and ended most of the state's bilingual education (prop 227). Similar actions were also occurring in Texas and other states. The disproportional numbers of minorities being held back from promotion and dropping out of school reflect racial divisions and inequalities and the role of schools as sorting mechanisms for US society.
President George Bush's «No Child Left Behind Act» requires greater accountability in testing and promoting students and more severe consequences for failing to score on standardized tests. A harsher policy of grade level retention has retarded the social development of students with deficient abilities to score on tests and the lack of funding by the Bush administration makes it difficult to provide needed tutoring of failing students, thus greatly increasing the number of minority and poorer students who cannot make it through high school. These policies mark a significant increase in a deficit-thinking model of education, where the students who fail are punished instead of helped.

Accompanying this positivistic wave is the corporate appropriation of progressive pedagogy under the label of instrumental progressivism. Uniting the business world with education is part of the co-optation of schools and the public sphere. Kevin Robins and Frank Webster (2001) explain that instrumental progressivism emphasizes competencies at the expense of content knowledge, increases monitoring and surveillance through excessive testing, and most importantly disables critical thinking of its political potential. The morphing of corporate interests with educational institutions is less restrictive than outright censorship, yet more pernicious in its potential to set a corporate agenda for public education, whereby students become commodities shaped to fit into the market economy as merely consumers and workers.

This merging of corporate America with public education can clearly be seen in the Partnership for 21st Century Skills, a public-private organization founded in 2002 by the US Department of Education, Microsoft Corporation, Apple Computer, Inc. and AOL Time Warner Foundation, to name a few. In a report released by this organization, media literacy is listed as a key learning skill. While this partnership offers the possibility of wide exposure for media literacy, the danger of appropriation through instrumental progressivism is clear. The focus on workplace productivity and the absence of a social justice agenda demonstrate the influence of business interests.

\section{Conclusion}

Critical literacy gives individuals power over their culture and thus enables people to create their own meanings, identities, and to shape and transform the material and social conditions of their culture and society. Many critical educators have been promoting these goals, including Len Masterman who 
has proposed that media education aim at critical autonomy, empowering students to be independently critical. Robert Ferguson suggests that our relationships with media are not autonomous, rather they depend on taking positions related to social contexts. Since we are always taking sides, Ferguson calls for critical solidarity that he describes as «a means by which we acknowledge the social dimensions of our thinking and analysis. It is also a means through which we may develop our skills of analysis and relative autonomy» (2001, p. 42). Critical solidarity means teaching students to interpret information and communication within humanistic, social, historical, political, and economic contexts for them to understand the interrelationships and consequences of their actions and lifestyles. If we combine critical autonomy with critical solidarity, we can teach students to be independent and interdependent critical thinkers, and no longer dependent on media.

Critical media literacy offers an excellent framework to teach critical solidarity and the skills that can challenge the social construction of information and communication, from hypertext to video games. Schools must change the way they teach and by instructing students to become empowered to analyze and use media to express their opinions in critical solidarity with the world around them. The basis of media literacy is that all messages are constructed, and when education begins with this understanding of the social construction of knowledge, the literacy process can expand critical inquiry into multiple forms of information and communication, including television programs, Internet, advertising, artificial intelligence, biotechnology, and books. Carmen Luke writes, «unless educators take a lead in developing appropriate pedagogies for these new electronic media and forms of communication, corporate experts will be the ones to determine how people will learn, what they learn, and what constitutes literacy» $(2000$, p. 71$)$.

Literacy is thus a necessary condition to equip people to participate in the local, national, and global economy, culture, and polity. As Dewey argued (1997), education is necessary to enable people to participate in democracy, for without an educated, informed, and literate citizenry, strong democracy is impossible. Moreover, there are crucial links between literacy, democracy, empowerment, and participation, and without developing adequate literacies, differences between «haves» and «have nots» cannot be overcome and individuals and groups will be left out of the emerging global economy, networked society, and culture.
Living in what Marshall McLuhan coined the global village, it is not enough to merely understand media, students need to be empowered to critically negotiate meanings, engage the problems of misrepresentations and underrepresentations, and produce their own media. Addressing issues of inequality and injustice in media representations can be a powerful starting place for problem-posing transformative education. Critical media literacy offers the tools and framework to help students become subjects in the process of deconstructing injustices, expressing their own voices, and struggling to create a better society.

\section{Appendix}

Christianity and Media Education

Corporations are not the only ones jumping on the media literacy bandwagon. Lutherans, Presbyterians, Catholics and other religious denominations are turning to media literacy as a tool in their battle against the secularization of society and control over «moral values».

Christian Media Literacy Institute: «Proclaiming the Gospel through Media Literacy». 〈http://www.cmli.org/〉

Presbyterian Media Mission. 〈http://www.pmm4u.org/start.cfm

Pauline Center for Media Studies - West.

〈http://www.paulinecenterformediastudies.org〉

Federal Funding of Media Education

At the beginning of this new millennium, the federal government funded the first ever media literacy grants. Only 17 projects across the country received this money from a joint venture between the Department of Education and the National Endowment for the Arts. The goal of the grants was to fund projects that integrate media literacy and the arts.

Currently, the US Department of Education is giving $\$ 800,000$ to the AMLA and Just Think Foundation to implement a three-year Media Arts education program in two middle schools in San Francisco as a model project to possibly replicate across the country. 


\section{US Media Literacy Organizations}

ACME, Action Coalition for Media Education (national ML organization, radical). 〈http://www.acmecoalition.org〉

AMLA, Alliance for a Media Literate America (national ML organization, liberal). 〈http://www.amlainfo.org

Center for Media Literacy. 〈http://www.medialit.org〉(sells ML material, offers training, creates curriculum etc.)

New Mexico Media Literacy Project (Bob McCannon, since 1994).

http://www.nmmlp.org/〉 (does teacher training, creates ML curriculum and more)

\section{Educational Institutions}

The USC Annenberg Center: Institute for Multimedia Literacy,

〈http://www.iml.annenberg.edu/〉 (new center at USC for training teachers in ML).

Media Education Lab at Temple University School of Communication and Theater http://www.reneehobbs.org/> (Renee Hobbs). The ME Lab offer classes on ML at the university, runs a weeklong ML summer institute as well as professional development for teachers in the Philadelphia area.

The Center for Media Studies, (Robert Kubey) School of Communication, Information and Library Studies at Rutgers, The State University of New Jersey. 〈http://www.mediastudies.rutgers.edu/>

The NW Center for Excellence in Media Literacy,

http://depts.washington.edu/nwmedia/〉 in Washington State with a focus on teens and health.

Project Look Sharp (Cyndy Scheibe) 〈http://www.ithaca.edu/looksharp/s, associated with Ithaca College, NY, provides teacher training and creates ML curriculum.

Webster University, in St. Louis, Missouri (Art Silverblatt) 〈http://www. webster.edu/medialiteracy/index.html > offers B.A. Media Communications with an Emphasis in Media Literacy and M.A. Media Communications with Emphasis in Media Literacy.

University of Massachusetts Boston.

http://www.ccde.umb.edu/certificates/cmt/〉, this is a Certificate in Community Media and Technology for students who already have a B.A.

Appalachian State University in North Carolina, (David Considine)<http://www.ci.appstate.edu/programs/edmedia/medialit/mlmasters.ht ml> offers a Master's of Arts in Educational Media and an annual summer institute in media literacy.

\section{Web Sites}

Media Literacy Clearing House, (Frank Baker) 〈http://medialit.med.sc.edu/ A web site with numerous ML resources.

Media Literacy Online Project, University of Oregon, Eugene, College of Education, (Gary Ferrington)

http://interact.uoregon.edu/MediaLit/HomePage〉 This web sites has ML articles and links.

National Telemedia Council 〈http://www.nationaltelemediacouncil.org/〉 NTC claims to be «the oldest professional media literacy organization in the US, having been founded in 1953» they publish a journal and sponsor conferences.

Media Literacy.com (Susan Rogers)

http://www1.medialiteracy.com/home.jsp〉 This web site is a collection of ML resources and articles.

Student Media Production that boast media literacy

Just Think Foundation, 〈http://www.justthink.org/> Media production with media literacy.

AnimAction: Awareness Through Animation,

http://www.animaction.com/> This LA based organization teaches kids to make anti-smoking cartoons, etc. 
Educational Video Center, NY (Steven Goodman)〈http://www.evc.org/〉 Youth video production with media literacy.

Boston YWCA: Youth Voice Collaborative, after school program in ML and youth media production. 〈http://www.ywcaboston.org/programs/yvc/〉

Alternative Media

Active Voice, 〈http://www.activevoice.net/about.html〉 Media professionals who create alternative media and conduct workshops.

Media Education Foundation, (Sut Jhally), 〈http://www.mediaed.org/> Creating and distributing videos on media, such as Tough Guise, Hijacking Catastrophe, etc.

Citizens for Media Literacy, 〈http://www.main.nc.us/cml/〉 A communitybased organization in Ashville, North Carolina that promotes democratic access and media literacy.

Stay Free! Magazine. 〈http://www.stayfreemagazine.org/ml/> This web site contains ML high school lesson plans and a regular zine. 